\title{
Properties of poly (4-nitro)triphenylamine-thiophene Composite based Cathode Material for Rechargeable Lithium-ion Battery
}

\author{
Xin Yue ${ }^{1, *}$, Jinsheng Zhao ${ }^{2}$, Lingqian Kongl, \\ ${ }^{1}$ College of DongChang, Liaocheng University, Liaocheng 252000, People's Republic of China \\ ${ }^{2}$ School of Chemistry and Chemical Engineering, Liaocheng University, 252059, People's Republic of \\ China \\ *E-mail: yuexin6100@163.com (X. Yue) lingqiankong@126.com (L. Q. Kong)
}

doi: $10.20964 / 2021.02 .02$

Received: 25 September 2020 / Accepted: 23 November 2020 / Published: 31 December 2020

\begin{abstract}
A triphenylamine-based conjugated polymer (PTPA-NO $\left.\mathrm{N}_{2}\right)-\mathrm{PTH}$ poly[4-(nitro)triphenylaminethiophene] with multiple active polymerization sites has been prepared as the cathode material. First, the crystal phase structure, surface morphology and element states were characterized by XRD, SEM and XPS in turn, the dispersed porous arthicstructure supply a rich electrochemical interface and ion channels to improve its electrode reactivity. By calculating the energy level of HOMO and LUMO orbitals, we find that the conductivity and conjugation ability are enhanced. Then the electrochemical charge and discharge performance, CV and EIS of the battery were also tested, because of the nitro electronabsorbing functional unit are introduced in the triphenylamine skeleton, the copolymer perform a reversible specific capacity of $772.4 \mathrm{mAh} / \mathrm{g}$ with two significant charge-discharge voltage platforms under different reaction mechanisms after 500 cycling, even when the current density is $1600 \mathrm{~mA} / \mathrm{g}$, this composite material still maintain a high capacity of $550 \mathrm{mAh} / \mathrm{g}$ with the efficiency $\geqslant 99 \%$.
\end{abstract}

Keywords: triphenylamine-based conjugated polymer; nitro; electrochemical; lithium-ion battery

\section{$\underline{\text { FULL TEXT }}$}

(C) 2021 The Authors. Published by ESG (www.electrochemsci.org). This article is an open access article distributed under the terms and conditions of the Creative Commons Attribution license (http://creativecommons.org/licenses/by/4.0/). 